\title{
Linking Primary Care to the Community: A Study of Pediatric Practices in Florida
}

Caprice Knapp $^{1 *}$, Vanessa Madden ${ }^{1}$, Ivana Sehovic ${ }^{2}$, Daniel Fernandez-Baca ${ }^{1}$, Jacqueline Baron-Lee ${ }^{1}$, Ruth S. Gubernick ${ }^{3}$, Cristina Pelaez ${ }^{4}$, and Gwendolyn Quinn ${ }^{2}$

${ }^{1}$ University of Florida, Department of Health Outcomes and Policy, USA

${ }^{2} H$. Lee Moffitt Cancer Center, USA

${ }^{3} R S G$ Consulting, USA

${ }^{4}$ University of South Florida, USA

*Corresponding author: Caprice Knapp, Department of Health Outcomes and Policy, 1329 SW 16th St, Gainesville Florida 32610, USA, Tel: (352) 265-2517; Email: caprice1@ufl.edu

Received date: Dec 12, 2013, Accepted date: Feb 17, 2014, Published date: Feb 25, 2014

Copyright: (C) 2014 Knapp C, et al. This is an open-access article distributed under the terms of the Creative Commons Attribution License, which permits unrestricted use, distribution, and reproduction in any medium, provided the original author and source are credited.

\begin{abstract}
Background and Objectives: Linking primary care practices to community entities is critical for providing comprehensive and continuous care. The patient centered medical home (PCMH) should facilitate linkages to the community. Our study aims to understand what challenges pediatric primary care practices in Florida face in developing these linkages.

Methods: Interviews were conducted with three-person core project teams working in 20 pediatric practices across Florida. All practices are participating in a longitudinal, PCMH demonstration project.

Results: At baseline, most practices reported positive connections with specialists, but about half reported insurance as the main barrier. Practices reported both negative and positive aspects of their connection to hospitals and emergency rooms. While some practices saw the emergency room as source of referral back to their practice, others felt that hospitals or emergency rooms did not communicate well or collaborate in patient care. Most practices felt that current communication with traditional and special schools was insufficient (paperwork-based) and infrequent (as-needed basis), and that a more formal and proactive system was needed. While most practices were able to provide numerous examples of their involvement in the community, their responses indicated a lack of organization or planning for future events. The majority of practices found it easier to describe one-time, past events rather than provide a list of current or recurring projects.
\end{abstract}

Conclusions: Integration on all levels is fundamental to the PCMH. Our study demonstrates that PCMH facilitators and accreditation agencies must take into account the varying barriers and infrastructures present in a practice's community when providing effective strategies for coordinated care.

Keywords: CHIPRA; Community outreach; Interviews; Collaborative care

\section{Introduction}

In recent years, healthcare practices, organizations, and policymakers have emphasized and promoted the transformation of traditional primary care in the United States to a patient-centered medical home (PCMH) model of primary care. In 2007, the American Academy of Family Physicians (AAFP) [1], American Academy of Pediatrics (AAP), American College of Physicians, and the American Osteopathic Association published seven core principles of a PCMH: a personal physician for each patient, care throughout all stages of illness, coordinated and integrated care, quality and safety at each level of care, expanded access to care, and payment that accounts for the value added. In addition, the AAP noted that a PCMH for infants, children, and adolescents should be accessible, continuous, comprehensive, family centered, coordinated, compassionate, and culturally effective [2]. Based on this framework, a PCMH should result in cost-effective and efficient care.
Evidence on the effectiveness of the PCMH is growing. A 2008 review by Homer and colleagues of the pediatric $\mathrm{PCMH}$ literature noted that the evidence is often focused on specific components instead of being comprehensive [3]. Of the 33 articles reviewed 12 assessed care coordination with community resources, 14 care coordination with specialists, 25 care planning, and 2 population monitoring. It is not surprising that fewer studies assessed coordination with community resources as this is can be interpreted and measured in several ways. When it comes to establishing community linkages the AAP recommends "interaction with early intervention programs, schools, early childhood education and child care programs, and other public and private community agencies to be certain that the special needs of the child and family are addressed [2]. Yet, actual interactions range from simple awareness to formal written policies.

The few studies that have investigated community linkages suggest that consistent involvement and familiarity with a patient's community contributes to better coordination of care, improved health behaviors, increased family centeredness, and efficient and 
effective use of resources [4-6]. The specific effects of these community linkages are often difficult to tease out as they are often studied in tandem with other aspects of the medical home. Research suggests that the child's primary care provider is in the best position to work closely with the school to ensure full inclusion of the child in regular classroom and physical education activities, as well as identifying key school contacts who play a vital role improving the child's quality of life [7]. Practices that develop a meaningful relationship with schools could benefit through improved bi-directional communication about symptoms, management, and treatment adherence. Specific to the $\mathrm{PCMH}$, other studies suggest that the $\mathrm{PCMH}$ is positively associated with school engagement $[8,9]$, ease of use of community services [10], improved access to specialists through referrals $[11,12]$, and decreased need for social support [11]. Although insightful, most of these studies are quantitative and cannot comment on why linkages are difficult to develop.

Our study addresses gaps in the pediatric literature about community linkages by attempting to ascertain exactly what forms of community linkages practices engage in prior to any formal PCMH intervention. We used qualitative, baseline interview data from 20 practices participating in Florida's Pediatric Medical Home Demonstration project to 1) understand their perspectives on community linkages and 2) identify strategies that can be used in the project to develop community linkages. Given that these interviews were conducted at baseline, we hypothesized that most practices would not have meaningful linkages with their community in place but that they would view them as an important component of the PCMH. Results from this study are critical for those who facilitate practices in becoming a PCMH and for policymakers to avoid building PCMHs in isolation; a practice that could perpetuate fragmentation in health care.

\section{Methods}

\section{Sample}

The Florida Pediatric Medical Home Demonstration Project is a five-year project that began in 2011 as part of the state's Children's Health Insurance Program Reauthorization Act (CHIPRA) grant. The project has two parts: 1) a facilitated quality improvement project lead by the AAP's Quality Improvement Innovation Network (QuIIN) [13] and 2) an independent, multi-stakeholder evaluation.

Commencing in July 2011 practices were recruited through several email list serves, such as the Florida Chapter of the AAP and provider networks of the Children's Medical Services Network, and two informational webinars conducted by the AAP. Practices had to meet three selection criteria: (i) A minimum of 100 children with special health care needs (CSHCN) in their panel, (ii) Participation in Medicaid or Florida KidCare, and (iii) No former participation in the state's only previous medical home implementation project that was conducted in Duval County in 2009. Practices could be pediatric, family medicine, hospital-based, or federally qualified health centers.

As part of the application process for the demonstration project, practices identified a three-member core project team that included a lead physician and two other team members (regardless of their role in the practice) who would commit to participate in learning activities, act as medical home champions, and participate in the evaluation activities. Twenty practices who met the inclusion criteria were selected to participate in the project in July 2011.

\section{Procedure}

Practices were informed that the demonstration project included an annual evaluation to be conducted by an independent evaluator. The four-year evaluation includes components such as annual surveys with the core project team, staff, parents whose children receive care at the practices, assessments of practice-level results of the CHIPRA core measures using administrative data, and qualitative interviews conducted with the core project team during site visits to their location.

Qualitative interviews were arranged between September and November 2011. These interviews collected baseline information from the practices and will be used in future longitudinal analyses, as well, to identify changes and describe challenges in the PCMH transformation. Two study team members conducted the interviews which lasted between 45 minutes and one hour. No incentives were given to participants. An interview guide was created after a review of the pertinent literature and was approved by the project's Expert Group. The interview guide was also piloted with a pediatrician for both timeliness and clarity. Interviews were audio recorded and transcribed verbatim. This study was approved by the Institutional Review Board at the University of Florida (\#80-2011).

\section{Measures and analyses}

The broad domains of the qualitative interview included 1) initial feeling about transforming into a medical home, 2) internal factors that made them unique, 3) external factors that affected the practices, and 4) community linkages. We regard community linkages as connections to any person, group, or institution outside of the practice. Community was not explicitly defined for the practices but rather core practice teams were asked about their current connection to the healthcare system, traditional and special schools, and interactions with patients in community settings (such as health fairs). They were also asked to gauge their influence on the healthcare system and their community. The constant comparison method was used to analyze the data [14]. Once themes and categories were established, emerging patterns were identified. Responses were coded using ATLAS.ti (version 7.0.85, 2013, GmbH, Berlin, Germany), a software program for analysis of qualitative data. Participant responses were assigned codes representing specific a priori themes identified in the interview guide. Additional codes representing emergent themes were also developed. Preceding formal coding using ATLAS.ti, two transcripts $(10 \%)$ were hand-coded separately by three researchers in order to ensure inter-rater reliability (IRR). The IRR was calculated as 0.95 for both specific content coding and general theme coding.

\section{Results}

\section{Qualitative results}

Table 1 describes the participating practices. Five practices had one physician (solo), six practices had three or less physicians (small), and nine practices had more than three physicians (large). Twelve practices were classified as independent, six as hospital-affiliated, one as a Federally Qualified Health Center (FQHC), and 1 as university or medical school-affiliated. Six practices did not have electronic health records (EHR) at the time of the interview.

Core project teams from all 20 practices participated in the interviews. Themes regarding practice linkages to specialists, hospitals, 
schools, and the community emerged from the qualitative analyses. Type of practice is noted in parentheses after each quote.

\section{Connection to specialists}

Having an established process for specialist referral and follow-up is a crucial component of a medical home (Table 2).

Most practices reported positive connections with specialists, citing their affiliation or location as the main reason. Some practices, however, reported well-established connections with certain specialties, but felt that insurance barriers created poor or non-existent relationships with others. There were no notable differences by practice size or affiliation in regards to connection with specialists.

\section{Connection to hospitals}

Maintaining relationships with neighboring hospitals allows the practice to keep track of their patients' visits and develop community linkages that can be useful for both patients and staff (Table 3).

For practices with EHR, quicker access to patient information, such as emergency room visits, helped create a better relationship with hospitals. Practices reported both negative and positive aspects of their connection to hospitals and emergency departments. While some practices saw the emergency departments as a good source of referrals back to their practice, others felt that hospitals or emergency departments did not communicate well or collaborate in patient care. A few practices felt that large hospitals or major teaching institutions create a stronger sense of community.

\begin{tabular}{|l|l|l|}
\hline & Frequency & Percent \\
\hline Practice Size & 20 & \\
\hline Solo & 5 & $25.0 \%$ \\
\hline Small Practice (3 or less physicians) & 6 & $30.0 \%$ \\
\hline Large Practice (more than 3 physicians) & 9 & $45.0 \%$ \\
\hline Practice Type & 20 & $60.0 \%$ \\
\hline Independent Practice & 12 & $30.0 \%$ \\
\hline Hospital-affiliated Practice & 6 & $5.0 \%$ \\
\hline University or Medical School-affiliated & 1 & $5.0 \%$ \\
\hline FQHC & 1 & \\
\hline Electronic Health Records (EHR) & 20 & $70.0 \%$ \\
\hline Adopted & 14 & $30.0 \%$ \\
\hline Not Adopted & 6 & \\
\hline
\end{tabular}

Table 1: Practice characteristics

\begin{tabular}{|l|l|}
\hline Themes & Quotes \\
\hline $\begin{array}{l}\text { Affiliation } \\
\text { Location }\end{array}$ and & $\begin{array}{l}\text { "We do have access to lots of specialists and services that most private offices don't have. And we are in an academic environment, that's the } \\
\text { other thing." } \\
\text { (small, hospital-affiliated) } \\
\text { "I mean, for us, being that we're right here ... in the hospital, so... we have the connection there just by location." (large, hospital-affiliated) } \\
\text { "Being a private practice, we are connected with just about... everybody out there." (large, independent) }\end{array}$ \\
\hline
\end{tabular}

While there were no notable differences by practice size, hospitalaffiliated practices would naturally have a stronger connection to hospitals.

\section{Connection to schools}

Since all the practices in this investigation serve a pediatric population, it was important to assess the level of interaction with neighboring schools (Table 4).

Although many practices were able to identify some kind of connection with nearby traditional or special schools, most felt that current communication with schools was insufficient (paperworkbased) and infrequent (as-needed basis), and that a more formal and proactive system was needed. All practices expressed a desire to improve their connection with schools but were unsure how to become more proactive or lacked the resources to do so. Several barriers were identified, including community distrust, lack of school nurses, lack of knowledge among parents in regards to learning disabilities and the law, and difficulty interacting with certain types of schools. There were no notable differences by practice size or affiliation in regards to connection with schools.

\section{Connection to the community}

While most practices were able to provide numerous examples of their involvement in the community, their responses indicated a lack of organization or planning for future events (Table 5). 
Citation: Knapp C, Madden V, Sehovic I, Fernandez-Baca D, Baron-Lee J, et al. (2014) Linking Primary Care to the Community: A Study of Pediatric Practices in Florida. J Gen Pract 2: 147. doi:10.4172/2329-9126.1000147

Page 4 of 7

Insurance Barriers

"But when you get to like derm and ortho, it just really depends on what insurances they take, and do they take it for this reason or do they take it for that reason, and you only see this one if they have this, and... it can be a nightmare." (small, independent)

"We have our specialists that we know will do the Medicaid and ... we have a very close relationship with them and I make sure that when I talk to their staff I am very polite, I'm very nice because I know that is my resource." (solo, FQHC)

"So sometimes it's not as easy ... while on one hand we have good relationships with some of the specialists and I mentioned that even though they don't take Medicaid, if we call, they will see our patient, but there are clearly other specialties that don't care..." (large, independent)

Table 2: Connection to Specialists

\begin{tabular}{|c|c|}
\hline Themes & Quotes \\
\hline Quick Access & $\begin{array}{l}\text { "I have privileges in ... the local hospitals and also we have access... we can log in online and access our patients or access who is seen in } \\
\text { the ER. We can also order labs in the local hospital and access it online, same thing with the local labs." } \\
\text { (small, independent) } \\
\text { "They have read-only access, but they can actually pull up our EHR and they can look at the last office visit, they can look at their history, } \\
\text { they can look at their medications." } \\
\text { (large, hospital-affiliated) }\end{array}$ \\
\hline Emergency Departments & $\begin{array}{l}\text { "Some of our hospitals like to use our MediPass number ... at the beginning of the month and they just kind of ... admit and they don't really } \\
\text { call. That bothers me a great deal because I, (a) think our patients over utilize the emergency room instead of coming to us and (b) } \\
\text { because they tend to refer out to specialists without waiting for our opinion about the situation." } \\
\text { (large, university or medical school-affiliated) } \\
\text { "Nearby hospitals, I guess has been a little different from someplace like Orlando because there is not really any place around here that } \\
\text { admits pediatrics. So with nearby hospitals our relationship has mostly been with the emergency room, and they've been a very good } \\
\text { source of referrals." } \\
\text { (solo, independent) }\end{array}$ \\
\hline Sense of Community & $\begin{array}{l}\text { "Well, I think that over time there's been a decline in ... exchanges within the medical community ... but we have } 14 \text { hospitals, ten of which } \\
\text { are for-profit. They're all, basically, small hospitals. The largest is } 200, \text { maybe a } 300-b e d \text { hospital, so there's no major teaching institution, } \\
\text { no major, you know, 800-bed hospital. That is what, really, I think, drives quality, drives community, in most areas." } \\
\text { (large, independent) }\end{array}$ \\
\hline
\end{tabular}

Table 3: Connection to Hospitals

\begin{tabular}{|c|c|}
\hline Themes & Quotes \\
\hline Communication & $\begin{array}{l}\text { "I don't think we stay connected as we could be or should be. I think it's more of an as-needed basis, just patients here right } \\
\text { now, they need this form filled out, or they need - they have a question on their asthma medications, I mean as far as being } \\
\text { proactive and getting proactively involved, I don't think we do that enough." } \\
\text { (small, hospital-affiliated) } \\
\text { "We have this kind of working relationship with schools and stuff, which is very paperwork driven, but there's no kind of } \\
\text { thought sharing or how could we do anything better." } \\
\text { (large, hospital affiliated) } \\
\text { "Yeah ... sometimes with the schools, I almost feel like an adversarial relationship between us and the schools, and } \\
\text { especially for kids that are having school problems. And ADHD ... the schools are overwhelmed and ... just make them go } \\
\text { to the doctor and get a pill, and sometimes that's the right answer if they truly have straightforward ADHD, but a lot of times } \\
\text { you hear, as the doctor, I'm hearing things that make me think ..., there may be more of an IQ problem or a learning } \\
\text { disability or an educational problem." } \\
\text { (large, hospital-affiliated) }\end{array}$ \\
\hline Identified Barriers & $\begin{array}{l}\text { "[Our] County does not have school nurses in their schools so that's a challenge." } \\
\text { (small, hospital-affiliated) } \\
\text { "We had a very difficult time breaking in to the community because they really were not trusting of us and we didn't have a } \\
\text { way to bond with them appropriately to get them to kind of trust us." } \\
\text { (large, independent) } \\
\text { "And many of these people don't have any idea about learning disabilities, the law, so there are many times we have to help } \\
\text { them with that, that this is the IDEA or a 504, and we have to sit down and explain to them." } \\
\text { (solo, independent) } \\
\text { "I think these high schools have so many thousands of kids that counseling off is not quite approachable and they've often } \\
\text { told us that they don't have permission to speak to us. So that's where l've seen problems in high school. Younger schools } \\
\text { no." }\end{array}$ \\
\hline
\end{tabular}


Table 4: Connection to Schools

\begin{tabular}{|c|c|}
\hline Themes & Quotes \\
\hline One Time Events & $\begin{array}{l}\text { "And again, when we had better resources ... there has been, from time to time, this is, like, sparingly ... projects. There has } \\
\text { been workers that gone from house, door to door enrolling them in Medicaid, Kid Care or programs, and also we have had } \\
\text { gone to YMCA local, whatever communities ... this has gone... I'm not aware whether it's still taking place. } \\
\text { (small, hospital-affiliated) } \\
\text { "Yeah, besides the sponsoring some of these, we also take part in health fairs. I can't remember the last one we did, but we } \\
\text { used to get booths when they have health fairs at the community college and all that." } \\
\text { (small, independent) }\end{array}$ \\
\hline Barriers to Involvement & $\begin{array}{l}\text { "It was fun, but in terms of attracting more patients it totally didn't work ... So we haven't been doing anything like that lately } \\
\text { because it's so time consuming, but perhaps later." } \\
\text { (solo, independent) } \\
\text { "Ronald McDonald Care Mobile ... has offered to go out to schools in [our county]. They have refused because they don't } \\
\text { want us doing sexuality type stuff if it's an adolescent." } \\
\text { (large, university or medical school-affiliated) } \\
\text { "We used to have a librarian who used to sit there and give the kids books as they came in and read to them and colored } \\
\text { with them, but unfortunately, the county had to pull that service away." } \\
\text { (small group, hospital-affiliated) }\end{array}$ \\
\hline Ideas for Improvement & $\begin{array}{l}\text { "I think we could do better with that. I don't know, I mean, I know that there's a lot involved with that, financial and } \\
\text { everything, and I think we, especially with you and the school board and such, I think we do a lot of things that maybe I'm } \\
\text { not even aware of. But, I think we could probably, as a group, put ourselves out there a little bit more. } \\
\text { (large, independent) } \\
\text { "But as far as really - we don't have any - we're not real active in - I mean we belong to [Our] County Medical Society. We } \\
\text { could do better at that." } \\
\text { (large, independent) } \\
\text { "I wonder if we could do more preventative care somehow. Even, going around high schools. How about teenagers, even to } \\
\text { properly brush their teeth, they don't hit their gums. Silly things like that make such a difference." } \\
\text { (small, independent) }\end{array}$ \\
\hline
\end{tabular}

Table 5: Connection to the Community

Many practices found it easier to describe one-time, past events rather than provide a list of current or recurring projects. Barriers to community involvement included poor response from the community, issues with sexuality and adolescents, lack of resources, and lack of time. Some practices recognized this gap in community involvement and wanted to improve connections in the future, but did not have any definitive plans or were unsure how to implement their ideas.

Overall, solo practices were able to identify more specific, local ways to influence their community, while small group practices responded with the most variety. By comparison, large practices tended to participate on a bigger scale (i.e. larger community outreaches, national projects/memberships).

\section{Discussion}

This study aimed to understand pediatric practices' perspectives on community linkages and identify strategies that can be used to develop community linkages. Although these interviews were conducted in the first year of the project, we found that some practices did have meaningful linkages with their community but that the linkages were primarily to specific specialty practices and, in a few cases, to emergency rooms at local hospitals. The findings expand the understanding on enablers and barriers related to community linkages in the following ways.

Connections to specialists are challenging, especially for practices not affiliated with a hospital. Even when linkages are made they tend to be established and meaningful for a handful of specialists. Specialty groups can be engaged in a number of ways such as sending introductory letters, inviting specialists to describe their services, or developing formal agreements. Successful interactions will depend on characteristics and past experiences of the primary care practice and the specialists. Practices may benefit from developing a list of specialists, as well as the insurance they accept, that they have meaningful relationships with, keeping that list up to date, and sharing the list with families. Since patients already expect their provider to be familiar with community resources and the local environment, [5] providing these resources through the practice itself would ensure greater familiarity and ability to meet the needs of patients and minimize healthcare fragmentation.

When discussing linkages to the community, hospital emergency departments were mentioned by many of the participants. Although these linkages are easier when the physician has access to the hospital's EHR, either through affiliation with the hospital or through privileges, other strategies exist that can be mutually beneficial. Hospitals have the incentive to keep patients out of the emergency department and 
this should be accomplished by the PCMH model. As practices take the steps toward becoming a PCMH they can become a resource for emergency department referrals.

Linkages between practices and both specialists and emergency rooms may become easier as the spread of EHR and other health information exchange systems makes the effort to establish these connections much easier. While these systems are often expensive and require a steep learning curve, the move towards their adoption is evident even in our sample. Given that PCMHs rely on effective and efficient communication, EHRs provide a promising outlook for community linkages with the healthcare systems.

Practices also noted that connections to schools were among the most difficult. This was the one area where practices did not have many examples of successes or have ideas on how to foster these connections. The challenges are amplified by the fact that most practices serve children who attend many schools in the area and that high schools especially seem to be unresponsive. In these circumstances it may be helpful for practices to have written procedures that can be used to engage schools. This would include ideas about who to contact at the school, parental consents to share information, what information to offer school personnel, frequently used forms, and success stories. As some counties run school nurse programs, it may be beneficial to create in roads within existing healthcare systems in the schools.

Health fairs and membership in local societies were both mentioned and ways to connect to the community in general. Hosting health fairs is an effective way of attracting large numbers of people, generating a sense of partnership within the community, and enhancing communication between healthcare providers and the population they serve [15]. Significant barriers were lack of both funding and time. Practices might be able to overcome some of these barriers by supporting or sponsoring events instead of creating their own. Although not mentioned by the practices, linkages could be fostered with health plans and large employers in their area.

Community linkages are not only useful to the patient, caregiver, and practice staff but are also important in regulation and policy. For example, the leading $\mathrm{PCMH}$ recognition programs require that community linkages are established and documented. The National Committee on Quality Assurance evaluates practices on their ability to 1) maintain a community resource list, 2) track referrals, 3) arrange for mental health or substance abuse services, and 4) offer opportunities for peer support [16]. Likewise, the Medical Home Index, another tool used to measure practices, also includes two community outreach domains: community assessment of needs for children with special health care needs and outreach to agencies and schools [17]. Beyond recognition as a $\mathrm{PCMH}$, community linkages are critical in innovative health care delivery models such as Accountable Care Organizations (ACOs) [18]. ACOs are meant to align previously unrelated healthcare organizations within a community to improve efficiency, effectiveness, and quality of care [19]. Groups of primary care and specialty practices, hospitals, and ancillary health entities should work together to align objectives and coordinate care. As care is streamlined through interoperable electronic healthcare record (EHR) systems or written agreements for example, savings will be shared across the participating entities. To date, 32 ACOs have been implemented and evidence is not yet available on their impact $[20,21]$. However, it is important to note that primary care practices, which are the foundation to the entire $\mathrm{ACO}$, are expected to be recognized PCMHs.
As with all studies, ours has limitations that must be mentioned. Our study was conducted during the first year of the demonstration project. As such, practices may need more time to consider community linkages and implement strategies. Longitudinal data collection should allow for a better understanding of whether or not community-based linkages are focused on during the transformation and if so, what changes were made by the practices. In addition, because we did not formally define community for the practices it could be that there are elements of a community, such as substance abuse providers or peer support groups, that none addressed but are important [22]. However, research shows that participants typically nominate and share information that is important to them without formally defining constructs. Third, participating practices are all located in Florida and none are family practices. Pediatric practices may have different experiences with creating community linkages as might practices in other states. Finally, none of the practices in our demonstration have reached the point of applying for medical home recognition. Therefore, we are unable to quantify the 'return on investment' of building community linkages. Future research will address this issue.

Despite the limitations in our study we are able to extend the literature. Practices clearly define their communities by specialists, hospitals, and schools. Although we found a few established linkages, these were made by practices of all sizes and affiliation. This suggests that, even without facilitation, practices are engaging community members. These successes can be shared during a learning collaborative or e-mail listserv. If PCMH facilitators can provide helpful strategies or advice on creating community related infrastructure this would be a critical first step in ensuring that PCMH's are comprehensive. Connecting to the surrounding community should not be overlooked and should be considered a priority for any practice and definitely for PCMHs.

\section{References}

1. American Academy of Family Physicians, American Academy of Pediatrics, American College of Physicians, American Osteopathic Association (2007) Joint Principles of the Patient Centered Medical Home.

2. Medical Home Initiatives for Children With Special Needs Project Advisory Committee American Academy of Pediatrics. (2002) The medical home. Pediatrics 110: 184-186.

3. Homer CJ, Klatka K, Romm D, Kuhlthau K, Bloom S, et al. (2008) A review of the evidence for the medical home for children with special health care needs. Pediatrics 122: e922-937.

4. Etz RS, Cohen DJ, Woolf SH, Holtrop JS, Donahue KE, et al. (2008) Bridging primary care practices and communities to promote healthy behaviors. Am J Prev Med 35: S390-397.

5. Van Berckelaer A, DiRocco D, Ferguson M, Gray P, Marcus N, et al. (2012) Building a patient-centered medical home: obtaining the patient's voice. J Am Board Fam Med 25: 192-198.

6. Garg A, Sandel M, Dworkin PH, Kahn RS, Zuckerman B (2012) From medical home to health neighborhood: transforming the medical home into a community-based health neighborhood. J Pediatr 160: 535-536.

7. Kaslovsky R, Sadof M (2010) How to best deliver care to children with chronic illness: cystic fibrosis as a model. Curr Opin Pediatr 22: 822-828.

8. Stevens GD, Vane C, Cousineau MR (2011) Association of Experiences of Medical Home Quality with Health-Related Quality of Life and School Engagement among Latino Children in Low-Income Families. Health Services Research 46:1822-1842.

9. Stevens GD, Pickering TA, Laqui SA (2010) Relationship of medical home quality with school engagement and after-school participation among children with asthma. J Asthma 47: 1001-1010. 
Citation: Knapp C, Madden V, Sehovic I, Fernandez-Baca D, Baron-Lee J, et al. (2014) Linking Primary Care to the Community: A Study of Pediatric Practices in Florida. J Gen Pract 2: 147. doi:10.4172/2329-9126.1000147

Page 7 of 7

10. Baruffi G, Miyashiro L, Prince CB, Heu P (2005) Factors associated with ease of using community-based systems of care for CSHCN in Hawai'i. Matern Child Health J 9: S99-108.

11. Farmer JE, Clark MJ, Sherman A, Marien WE, Selva TJ (2005) Comprehensive primary care for children with special health care needs in rural areas. Pediatrics 116: 649-656.

12. Palfrey JS, Sofis LA, Davidson EJ, Liu J, Freeman L, et al. (2004) The Pediatric Alliance for Coordinated Care: evaluation of a medical home model. Pediatrics 113: 1507-1516.

13. http://www.aap.org/en-us/professional-resources/practice-support/qualityimprovement/Quality-Improvement-Innovation-Networks/Pages/QualityImprovement-Innovation-Networks-QuIIN.aspx.

14. Glaser BG. \& Strauss AL (1967) The Discovery of Grounded Theory: Strategies for Qualitative Research. New York: Aldine De Gruyter.

15. Dillon DL, Sternas K (1997) Designing a successful health fair to promote individual, family, and community health. Journal of Community Health Nursing 14:1-14.
16. http://www.ncqa.org/Portals/0/Programs/Recognition/RPtraining/PCMH \%202011\%20standards\%204-6\%20\%20workshop_2.3.12.pdf

17. Cooley WC, McAllister JW, Sherrieb K, Clark RE (2003) The Medical Home Index: development and validation of a new practice-level measure of implementation of the Medical Home model. Ambul Pediatr 3: 173-180.

18. Springgate BF, Brook RH (2011) Accountable care organizations and community empowerment. JAMA 305: 1800-1801.

19. Kreindler SA, Larson BK, Wu FM, Carluzzo KL, Gbemudu JN, et al. (2012) Interpretations of integration in early accountable care organizations. Milbank Q 90: 457-483.

20. U.S. Department of Health \& Human Services (2011) Affordable Care Act helps 32 health systems improve care for patients, saving up to $\$ 1.1 \mathrm{bln}$. Biomedical Market Newsletter 21:1-3.

21. http://innovation.cms.gov/initiatives/\#_Expand

22. Baron JM, Bluck S (2009) Autobiographical memory sharing in everyday life: Characteristics of a good story. International Journal of Behavioral Development 33:105-117. 